\title{
Antifouling and Anticorrosion Properties of Coatings based on Polyaniline Doped with Dodecyl Benzene Sulfonic Acid
}

\author{
Jiansan $\mathrm{Li}^{l}$, Jinye $\mathrm{Bi}^{1,{ }^{*}}$, Xinyue Wang ${ }^{1,{ }^{*}}$, Huajie Wang ${ }^{2}$, Xiangqi Huang ${ }^{1}$, \\ Yongmei $\mathrm{Li}^{3}$ and Guan Wang ${ }^{4}$ \\ ${ }^{1}$ School of Mechanical and Automotive Engineering, South China University of Technology, \\ Guangzhou 510640, PR China \\ ${ }^{2}$ Guangdong AntiCorrosion Association, Guangzhou 510640, PR China \\ ${ }^{3}$ Guangzhou Helee Surface Treatment Technologies Co.,Ltd, Guangzhou 510660, PR China \\ ${ }^{4}$ Guangdong University of Technology, Guangzhou 510006, PR China \\ *E-mail: 201921003338@mail.scut.edu.cn, xywang_scut@163.com
}

Received: 17 November 2021 / Accepted: 22 December 2021 / Published: 2 February 2022

\begin{abstract}
The polyaniline emeraldine-base form (PANI-EB) and polyaniline doped with dodecyl benzene sulfonic acid (PANI-DBSA) were prepared by chemical oxidation polymerization. The PANI-EB and PANIDBSA were characterized by Fourier transform infrared spectroscopy (FTIR), UV-Vis absorption spectroscopy (UV-Vis), X-ray diffraction (XRD), scanning electron microscopy (SEM)and water contact angle (WCA) measurements. Subsequently, polyaniline-acrylic resin coatings were prepared with these polyaniline materials as antifouling additives. The antifouling property of the polyaniline acrylic resin coatings was determined by immersion tests and the algae inhibition tests. The anticorrosion property of the PANI-DBSA coating with a better antifouling property was proven by electrochemical impedance spectroscopy (EIS) and measurement of the potentiodynamic polarization curve. The experimental results suggested that the PANI-DBSA coating shows good antifouling performance and anticorrosion performance. The mechanisms for the antifouling and anticorrosion performances conferred by PANI-DBSA are also discussed.
\end{abstract}

Keywords: polyaniline; dodecyl benzene sulfonic acid; acrylic resin; algal inhibition; antifouling coating; anticorrosion coating

\section{$\underline{\text { FULL TEXT }}$}

(C) 2022 The Authors. Published by ESG (www.electrochemsci.org). This article is an open access article distributed under the terms and conditions of the Creative Commons Attribution license (http://creativecommons.org/licenses/by/4.0/). 